\title{
História oral na historiografia: autoria na história*
}

\author{
Richard Cándida Smith**
}

Desde 2001, atuo como diretor do centro de história oral na Universidade da Califórnia em Berkeley (Regional Oral History Office - ROHO). O centro foi fundado em 1954. A primeira entrevista foi feita com Alice B. Toklas, originária de São Francisco, Califórnia, e companheira de Gertrude Stein, famosa poetisa norte-americana, também da Califórnia, embora as duas tenham vivido juntas muitos anos em Paris. Desde 1954, mais de 3500 entrevistas foram gravadas e transcritas. Elas falam de quase todos os assuntos possíveis sobre a história da Califórnia e do litoral do oceano Pacífico dos Estados Unidos, Canadá e México: a cultura, as empresas e indústrias, a vida agrícola, a ciência e tecnologia, a política, as relações com o mundo, e muito mais. ${ }^{1}$ Com as 500 entrevistas feitas entre 1865 e 1885, por Hubert Howe Bancroft, sobre a vida na Califórnia, desde a conquista espanhola até a conquista norte-americana, feitas com caciques-índios, líderes da comunidade californiana mexicana, pioneiros ianques e imigrantes do todo mundo, o acervo narra a história da Califórnia com relatos de primeira mão desde o fim do século XVIII até o presente. Eu acho que se trata de um recurso extraordinário com poucos similares no mundo e que está disponível aos pesquisadores com mínimas restrições. Nosso foco regional tem sido interpretado de

\footnotetext{
* Gostaria agradecer a Ana Maria Mauad e Marilena Pessoa pela ajuda com a preparação do texto em português. Sem a ajuda delas, não teria sido possível preparar a palestra para a apresentação em Recife. Porém, tenho responsabilidade por todas as falhas.

** Departamento de História da Universidade da Califórnia, Berkeley.

1 O site da Regional Oral History Office é http://bancroft.berkeley.edu/ROHO.
} 
forma ampla, de modo que, dada a centralidade das pessoas e das instituições californianas para muitos desenvolvimentos globais, o ROHO, com frequência, tem uma relevância global. Além disso, os acadêmicos da Califórnia já doaram para o arquivo mais de 7000 entrevistas que eles produziram no decurso das suas investigações.

Devido à importância do acervo, talvez seja estranho o fato de que eu seja o primeiro diretor do centro de história oral de Berkeley que é historiador e professor dessa universidade, pois as minhas antecessoras eram todas bibliotecárias. Nos Estados Unidos, o desenvolvimento da história oral teve duas bases importantes: de um lado, as bibliotecas que se utilizaram de entrevistas para aprofundar a documentação das elites; e do outro, os movimentos sociais cujo trabalho tem como proposta capturar o testemunho daqueles cujas experiências demonstram a justiça dos objetivos do movimento. Nesses dois casos, a história oral se distancia das questões de método histórico e interpretação. As palavras dos entrevistados, segundo tal perspectiva, devem substituir os esforços dos historiadores para descrever e interpretar o passado. Aqui o investimento de análise é substituído pelo de preservação, pois há vozes que se mantêm vivas para sempre fora da história.

Minha meta como diretor foi a de integrar a história oral à dinâmica de pesquisa e ensino, com vistas a superar a tradição anti-intelectual da história oral no meu país. Eu teria alguns exemplos de outras universidades norteamericanas; entretanto, encontrei na Europa e na América Latina exemplos mais significativos de como trabalhar academicamente no campo da história oral. Dentre os principais fóruns de debate, destaco a revista brasileira História Oral, com a qual aprendi muito sobre as pesquisas e debates desenvolvidos no Brasil. No entanto, foi numa situação em que eu era o entrevistado num projeto de história oral sobre ativismo estudantil que me dei conta do impacto desse campo de conhecimento na minha forma de pensar. Essa experiência é o foco da minha contribuição aqui. Espero que essa experiência bem pessoal consiga mostrar por que eu deposito tanta importância na interpretação hermenêutica da história oral para expor a historiografia às novas interpretações.

Em 1999, eu fui entrevistado por um projeto que pesquisava o ativismo estudantil na Universidade da Califórnia nos anos de 1960. Confesso que nunca tive uma posição de liderança no movimento estudantil, tampouco participava ativamente dos debates internos dos líderes estudantis. Eu era somente um estudante de base do movimento que tinha participado das atividades em defesa dos direitos civis, contra a política da guerra e do 
imperialismo do governo dos Estados Unidos depois de 1945. Mas o fato bem mais importante é que eu era muito jovem. Como se faz nos Estados Unidos, eu saí de casa para viver independentemente pela primeira vez quando entrei na faculdade em 1964. Lisa Rubens, a historiadora que estava organizando o projeto, achou que a minha experiência poderia iluminar os alunos mais jovens e politicamente menos sofisticados a como responder ao renascimento do ativismo social. ${ }^{2}$

No momento dessa entrevista eu já trabalhava no campo da história oral há cerca de 25 anos; portanto, já tinha uma experiência considerável como entrevistador, mas nunca como narrador de uma história oral. A experiência de estar do outro lado do gravador foi para mim tão intensa que desafiou alguns dos meus preconceitos sobre como o processo se desenvolve. Eu tinha muito a dizer, mas cada pergunta gerou certa confusão sobre como respondêla - uma reação que eu acho muito comum. Essa experiência teve um papel importante no meu pensamento posterior sobre o trabalho de um laboratório universitário de história oral.

As perguntas da entrevistadora foram incisivas. Ela estava profundamente familiarizada com as fontes primárias e secundárias relacionadas ao tema. Ela estava igualmente atenta ao que eu queria dizer, ou mais exatamente, ao que eu estava tentando dizer. $\mathrm{O}$ primeiro choque que senti foi pelo pouco que eu tinha a falar sobre algumas das questóes levantadas. Eu pude dizer umas frases e então nada mais. Falar a respeito de eventos importantes nos quais eu sabia que tinha estado presente muitas vezes revelou-se particularmente difícil. Minhas respostas eram lacônicas, cheias de frases curtas e tímidas, pois eu simplesmente não havia construído uma narrativa sobre o que eu havia vivido na época de estudante; em outras palavras, eu não havia elaborado um discurso para descrever os acontecimentos de então. Depois de diplomado, consegui trabalho, me casei, me tornei pai. Eu não estava vivendo nas minhas memórias dos anos estudantis. Sem discurso elaborado, eu era incapaz de ir além das fórmulas que se apresentavam na minha mente, apesar da sondagem cuidadosa da entrevistadora. A busca por palavras que fizessem sentido tinha apagado e substituído completamente a memória. Eu falei, mas não tenho lembrança nenhuma além das próprias palavras. Fui incapaz de

2 Para ler sobre a história do movimento estudantil na Universidade da Califórnia, ver Rorabaugh (1989) e Cohen e Zelnik (2002). Ver também o Free Speech Movement Oral History Project no site do ROHO. 
ampliar as minhas descrições. Tal limitação foi particularmente frustrante, pois percebi que respostas prontas e mínimas eram, basicamente, o que eu tinha a lhe oferecer.

Entretanto, diante de outras perguntas, eu experimentei um fluxo intenso de imagens e sentimentos. Naquele momento, a busca por respostas foi bem mais difícil, pois em face da riqueza de lembranças, as palavras me escapavam, e eu não sabia sequer por onde começar. Na verdade, eu tinha tanta coisa que poderia dizer, mas não tinha certeza de sua relevância. Eu tinha tanto a dizer, que entendi que o truismo, muitas vezes repetido, que um historiador oral oferece a oportunidade para o seu narrador de contar sua própria história, era impreciso. Eu tinha muitas, muitas histórias para contar, a maioria delas talvez irrelevante; no entanto, não poderia começar a responder sem ter em conta quais eram os objetivos mais profundos da entrevistadora - tanto os não declarados quanto os explícitos. Eu comecei a conjeturar o que os objetivos dela poderiam ser.

Algumas vezes, durante a entrevista, senti a forte necessidade de ir além dos objetivos da entrevistadora. Por exemplo, eu insistia em contar a história de como, em meados de 1964, a faculdade entrou na sua primeira grande greve estudantil em mais de 20 anos. A polícia municipal de Berkeley bateu na porta do apartamento às $10 \mathrm{~h}$ da noite. Uma vizinha, a polícia nos disse, se queixou de que havia mulheres visitando o apartamento onde os meus companheiros e eu morávamos. Berkeley tinha uma lei que considerava contravenção o ato de pessoas solteiras de sexo oposto ficarem juntas num apartamento ou numa casa depois de $9 \mathrm{~h}$ da noite - uma lei sobre a qual nada sabíamos, até que a polícia nos informou do seu direito de procurar, inclusive dentro de nossos armários, por moças que poderiam estar lá escondidas. Eu não tinha pensado sobre esse acontecimento, nem nunca conversara sobre isso desde 1964, mas o interesse da entrevistadora pela reputação de Berkeley como uma comunidade de atitudes bem liberais e não convencionais solicitou uma memória desaparecida havia 35 anos e uma necessidade de falar sobre o que tinha acontecido, bem como o sentimento profundamente pessoal por termos sido invadidos, uma sensação que eu tinha compartilhado com meus amigos naquele momento.

Como historiador, posso agora facilmente, e provavelmente com demasiada facilidade, explicar a importância do episódio para o clima no campus em 1964. Além disso, fica claro, hoje, o fato de que a polícia supervalorizava a questão moral, levantando o medo da sexualidade desenfreada dos jovens 
sem inibições, a fim de desacreditar um importante movimento na época em defesa de uma universidade pública melhor para servir com responsabilidade ao público em geral. No momento da entrevista, porém, eu não estava pensando como um historiador. Eu só me lembrava de episódios anedóticos, para os quais eu não tinha muita explicação. Com efeito, a tensão entre a experiência pessoal como uma forma de história vernácula e a análise histórica e profissional estava se debatendo dentro de $\mathrm{mim}^{3}$

Assim, enquanto eu refletia sobre o que havia aprendido em relação à dinâmica da experiência da entrevista, me dei conta de como são esses momentos, em que o diálogo entre historiador e narrador se aprofunda e se mistura, que fazem da história oral uma fonte importante para a história acadêmica.

A história oral prospera quando ultrapassa o modelo de simples coleção de histórias pessoais e se transforma em diálogo sobre o passado, estimulando novas interpretações históricas. O relato que eu conto só tem sentido quando estimula novas interpretações. Uma vez compartilhada, já deixa de ser a minha própria história. Cada entrevista pode ser um convite a uma cadeia de diálogos. Cria-se um elo que mantém vivos leitores e ouvintes na dinâmica da conversa, nas possibilidades de respostas, na busca de novas direções e possibilidades de interpretações das mais diversas sobre o que se viveu. A história oral pode democratizar o entendimento do passado porque nos permite imaginar a nossa experiência pessoal como algo que existe para ser compartilhado, como algo que poderia ser útil para uma comunidade de investigação mais ampla do que podemos imaginar. ${ }^{4}$

Quando em 2001 entrei para o Departamento de História, em Berkeley, e me tornei diretor do centro de história oral, organizei, a partir das minhas leituras e dessa experiência pessoal relatada, as seguintes metas para orientar a ação daquele setor:

1) desenvolver uma agenda de investigação e pesquisa para substituir a agenda anterior de coleções; ao invés de entrevistar pessoas sobre suas vidas, desenvolvemos projetos entrevistando, quando possível, dezenas,

3 A relação entre a história vernacular e profissional é tema desenvolvido no meu artigo "Analytic strategies for oral history interviews" (Smith, 2001), escrito logo após que Rubens me entrevistou.

4 Esse tipo de intercâmbio no processo da história oral se refere ao que Alessandro Portelli (1997, p. 6 e ss.) discute em seu livro, The battle of Valle Giulia: oral history and the art of dialogue, sobre o quanto "o contar histórias" transforma-se em "o dizer história". 
senão centenas, em projetos que exploram temas importantes para debates históricos e historiográficos de hoje em dia;

2) envolver estudantes em todos os projetos sempre que possível e incentivá-los a desenvolver seus próprios projetos com patrocínio oficial;

3) publicar todas as entrevistas anteriores (cerca de 2000), mais os projetos novos, na internet, com os resultados historiográficos preliminares, indicando o que trabalho suplementar pode explorar.

Cada objetivo desafiou os pressupostos do acervo bibliotecário que deu forma prática à história oral nas faculdades dos Estados Unidos desde que o historiador Allan Nevins fundou o Oral History Research Office dentro da Biblioteca Butler, na Universidade de Columbia, em 1948. Em minha opinião, o modelo de arquivo de história oral é fundamentalmente falho. Ao contrário de cartas, diários, ephemera ${ }^{5}$ ou manuscritos, as histórias orais não são papéis a serem recolhidos. As palavras e as observações registradas em histórias orais não são armazenadas em algum lugar à espera de recuperação. Não só porque elas não têm existência física antes do entrevistador e do entrevistado se sentarem juntos em frente a um gravador; elas não têm existência, nem mesmo imaterial. A forma de discussão sai da relação única dos indivíduos envolvidos, das perguntas colocadas, e de como o processo estimula tanto a expressão de fórmulas bem ensaiadas e do ressurgimento de impressões esquecidas, como, por exemplo, a minha lembrança da polícia visitando a minha casa em 1964. As hipóteses de investigação determinam o que os entrevistados escolhem dizer, ou mesmo do que se lembram.

As ênfases de outro entrevistador sobre o ativismo estudantil poderiam provavelmente ter me levado a escolher outras histórias para contar, e talvez outro incidente esquecido há muito tempo teria reaparecido em resposta a uma linha alternativa de questionamento. As conversas de história oral são muito diferentes dos outros tipos de fontes primárias porque numa conversa dizemos coisas que nunca poderíamos pensar em escrever. Se o entrevistador não entende o que um informante está dizendo, pode fazer perguntas para esclarecer confusões. Se o entrevistador souber que há controvérsias em relação a alguma questão ou tema, as perguntas podem ajudar a determinar a base da

5 Nas bibliotecas norte-americanas, ephemera designa fontes primárias tais como panfletos, folhetos, cartões postais e semelhantes (N. de E., segundo informação do autor). 
versão do informante, também considerando as possíveis interpretações que o narrador disponibiliza.

Em suma, as entrevistas de história oral devem ser produzidas e, portanto, os entrevistadores estão sempre envolvidos na investigação de se eles sabem ou não, se eles querem ou não. As gravações e transcrições podem e devem ser armazenadas em bibliotecas, ou melhor, na internet, mas a prática nos Estados Unidos de colocar os programas de história oral em bibliotecas de coleções especiais gerou uma compreensão invertida da história oral que valoriza mais um aspecto secundário do trabalho realizado. $\mathrm{O}$ sucesso foi medido sempre quantitativamente - literalmente, pelo número de horas gravadas, o número de páginas transcritas, bem como o número de títulos adicionados às prateleiras a cada ano. A importância dos materiais produzidos foi avaliada pelo número de publicações que citaram o material. Os registros de solicitações de citação foram mantidos religiosamente, mas não houve nenhuma avaliação de como os estudiosos e jornalistas tinham utilizado a história oral na construção de seus argumentos, ou de como o que haviam aprendido com o trabalho da história oral desafiou os entendimentos e as interpretações existentes.

Um colega me disse logo depois que entrei para a faculdade em Berkeley que a história oral é útil principalmente para a "cor local", mais para detalhes menores e nunca para novas perspectivas sobre o passado, nunca! Na verdade, a história oral nas universidades dos Estados Unidos sofreu muito porque o modelo de coleções prioriza pouca ou nenhuma avaliação intensa do conteúdo das entrevistas. A história oral fica fora da história.

As fontes orais tornam visíveis as formas de vida coletiva que são difíceis (embora não sejam impossíveis) de documentar de outras maneiras. Hoje, como no passado, as pessoas criam e mantêm uma vida compartilhada imaginativa quando se reúnem e conversam, seja na mesa da cozinha, no restaurante ou no botequim, ou mesmo nos corredores da universidade. Elas compartilham suas histórias e seus relatos a fim de desenvolver um entendimento comum sobre quem elas são. Esses entendimentos informais e coletivos permeiam todas as decisóes e também formam o pano de fundo de cada entrevista. Contos, pessoais e sociais ao mesmo tempo, fornecem evidências para a reconstrução das comunidades, das suas preocupações anteriores e dos conflitos do passado. A história oral permite a recuperação das ideias que foram importantes, mas não bem documentadas em papel ou fontes literárias. Minha lembrança de quando a polícia veio para investigar se havia membros 
do sexo oposto no meu quarto desapareceu da minha memória porque, em muito pouco tempo, a ideia de que a polícia pudesse controlar a vida sexual dos estudantes universitários tornou-se um absurdo. $\mathrm{O}$ evento em si não teve mais pertinência na vida cotidiana.

Em 1964, entretanto, a ocorrência foi um lembrete chocante de que, apesar dos imperativos sociais norte-americanos que levam os jovens a lutar por autonomia pessoal, os limites de controle de comportamento pessoal que as entidades coletivas ainda possuíam eram pouco claros e estavam mudando. Naquele momento, a visita da polícia procurando namoradas escondidas foi um acontecimento sobre o qual meus companheiros e eu conversamos incessantemente, um fator que contribuiu para que eu pudesse relembrar o evento 35 anos depois. O episódio não teve nada a ver diretamente com o movimento estudantil; ele, de fato, nunca se encaminhou a uma queixa formal. No entanto, o choque do evento repercutiu a raiva que muitos sentiram quando os administradores tentaram limitar os direitos dos estudantes de organizar de forma independente a sua participação na vida política nacional. Limites na liberdade pessoal, limites nos direitos de cidadania, no imaginário havia limites em todas as partes - uma impressão que reforçou a militância e uma determinação de quebrar os limites. Não foi o resultado que os administradores da universidade nem a polícia desejaram.

A natureza da linguagem oral compromete o objetivo de captar impressões diretas do passado. A linguagem comunica porque cria a "experiência" em formas convencionais. Os historiadores que trabalham com fontes orais, muitas vezes, falam sobre a memória e em como acessar a memória mais profundamente. Esse é um legado da falácia fotográfica incentivada por conceitos de arquivamento. Conceitos como hábito e fórmulas linguisticas são mais pertinentes para a formação de padrões da fala que venham a ser registrados como depoimentos orais. Quanto mais se fala de alguma coisa no passado, mais fácil será repetir as palavras aprendidas. Os relatos orais tendem a ser preenchidos com frases já memorizadas. A narração separa os falantes da experiência original, ao mesmo tempo em que a torna mais acessível. Se um pesquisador está à procura de uma perspectiva pessoal que vai além das convenções da comunidade, ele terá que interromper os hábitos, mas corre o risco de reduzir o narrador ao silêncio.

Além disso, os relatos orais sintetizam os eventos complexos numa imagem simples que será facilmente entendida. Os elementos individuais da memória substituem os processos complexos. Os relatos orais, por sua natureza, 
são simbólicos. O objetivo é comunicar um julgamento sobre o que aconteceu; convidar outra pessoa para compartilhar a perspectiva emocional do narrador. Paul Ricoeur (1984, p. 37) argumentou que "A interpretação da ação governa a qualidade ética das personagens." O julgamento ético determina tudo o que é dito. Mas o símbolo é uma forma sintética de compreensão. Não é analítico. Não pode explicar; só pode julgar. Sob uma perspectiva analítica, a fala é incompleta, mas por isso a fala sempre estimula mais a falar. Os relatos orais estão sempre procurando uma compreensão mais ampla através de um processo contínuo de reinterpretação.

Quando um pesquisador e um narrador se sentam para conversar sobre o passado, duas maneiras muito diferentes de pensar sobre o passado começam a se comunicar. Isso pode levar a um avanço cognitivo para ambos, se o historiador convidar o entrevistado a colaborar na interpretação do passado. As diferenças que surgem para a compreensão do passado abrem a possibilidade de uma intersubjetividade expandida. A ligação entre a realidade pessoal com os modelos acadêmicos de mudança histórica é uma das características que atrai os estudantes para a história oral. Em colaboração com especialistas, eles podem explorar e reconstruir o passado com um maior nível de sofisticação. O movimento da história oral tem promovido a democratização da história. E é dessa forma que os programas universitários de história oral podem contribuir: com a expansão e a continuação de conversas sobre o passado, incluindo cada vez mais pessoas que sentem a necessidade de participar do debate e mantê-lo vivo.

\section{Referências}

COHEN, R.; ZELNIK, R. E. (Ed.). The Free Speech Movement: reflections on Berkeley in the 1960s. Berkeley: University of California Press, 2002.

PORTELLI, A. The battle of Valle Giulia: oral history and the art of dialogue. Madison: University of Wisconsin Press, 1997.

RORABAUGH, W.J. Berkeley at war: the 1960s. New York: Oxford University Press, 1989.

RICOEUR, P. Time and narrative. Chicago: University of Chicago Press, 1984. v. 1.

SMITH, R. C. Analytic Strategies for Oral History Interviews. In: GUBRIUM, J. F.; HOLSTEIN, J. A. (Ed.). Handbook of interview research. Beverly Hills: Sage, 2001. p. $711-732$. 
Resumo: Este artigo apresenta uma breve história do Regional Oral History Office da Universidade da Califórnia, Berkeley. Ele critica o enfoque de recolha, que dominou o trabalho até 2001, e propõe um modelo alternativo com base em um foco de investigação. A experiência do autor de ter sido entrevistado para um projeto de história oral sobre ativismo estudantil na década de 1960 fornece um ponto de partida para pensar a história como uma cadeia de interpretações do passado compartilhadas e crescentes através de diálogo.

Palavras-chave: história oral, hermenêutica, lembrança e diálogo.

\title{
Oral history in historiography: authorship in history
}

\begin{abstract}
This paper presents a brief history of the Regional Oral History Office at the University of California, Berkeley. It critiques the collection-building focus that had dominated work until 2001 and proposes an alternative model based on a research focus. The author's experience having been interviewed for an oral history project on student activism in the 1960s provides a starting point for thinking about history as a chain of dialogue sharing interpretations of the past.
\end{abstract}

Keywords: história oral, hermeneutics, memory and dialogue.

Recebido em 25/10/2010

Aprovado em 20/12/2010 